\title{
THE ROLE OF PET/CT WITH 11C-METHIONINE IN CONTEMPORARY NUCLEAR MEDICINE
}

DOI: 10.36740/WLek202009234

\author{
Maciej Kołodziej, Barbara Bober, Marek Saracyn, Grzegorz Kamiński \\ DEPARTMENT OF ENDOCRINOLOGY AND ISOTOPE THERAPY, MILITARY INSTITUTE OF MEDICINE, WARSAW, POLAND
}

\begin{abstract}
Positron emission tomography (PET/CT) is a non-invasive molecular imaging technique using isotopes with a short half-life usually in combination with chemical compounds. The most commonly used PET/CT tracer is 2-fluoro-2-deoxy-D-glucose labeled with fluorine (18-FDG). It is used mainly in oncological diagnostics as well as myocardial viability, epilepsy and inflammatory diagnostics. The tracer less commonly used in PET/CT could be carbon-labeled methionine (11C-MET). It is mainly used in the diagnosis of focal lesions in the central nervous system. There are also reports of the use of this tracer in diagnostics of the primary, secondary and tertiary hyperparathyroidism as well as multiple myeloma. This tracer may also be used in the diagnosis of lymphoproliferative diseases and solid tumors, although there is no clear evidence of its advantage over 18-FDG. Conclusion: Significant difficulties in the production and transport of this tracer and lack of reimbursement of this type of procedure in Poland limits the use of this tracer for scientific research.
\end{abstract}

KEY WORDS: PET/CT, methionine, hyperparathyroidism, multiple myeloma, brain tumor

Wiad Lek. 2020;73(9 p. II):2076-2079

\section{INTRODUCTION}

Positron emission tomography (PET/CT) is a non-invasive diagnostic technique that uses short-lived, beta plus isotopes, which, thanks to the combination of substances naturally occurring in the human body, allows to track selected metabolic pathways and cell functions quite precisely. The most common tracer used in PET/CT diagnostics in Poland and other countries is fluoride-18 deoxyglucose (18-FDG), which is widely used in oncology, cardiological, neurological and inflammatory diagnostics [1]. Among the other tracers, carbon-11 labeled methionine (11C-MET) deserves attention. Methionine is one of the exogenous amino acids, isolated for the first time in 1921 by John Howard Mueller, mainly used for the synthesis of proteins, and as a cofactor for the transfer of carbon residues, and for energy production by incorporating into the citric acid cycle $[2,3]$. To obtain a tracer useful for PET/CT one of the stable carbon atoms in a methionine molecule is replaced by an 11-C isotope atom with a half-life of $20.4 \mathrm{~min}$ and a maximum radiation energy of $0.96 \mathrm{MeV}$ in the cyclotron as a result of the reaction between nitrogen and protons [4]. 11C-MET is a marker whose transport over considerable distances is technically impossible due to its short half-life. It is usually used in departments equipped with a cyclotron in which this tracer is produced. 11C-MET is most widely used in neurooncological diagnostics, as well as in the hematology and endocrinology $[5,6]$. The short half-life means that the exposure to ionizing radiation of a patient undergoing a diagnostic procedure using 11C-MET is lower than in the case of much more frequently performed procedures with 18-FDG, and the critical organs for this marker are the pancreas and liver, in which the physiological uptake of $11 \mathrm{C}$-MET is highest due to the anabolic functions of these organs, as well as the bladder due to urinary marker excretion $[7,8]$. The examination is performed approximately 10-20 minutes after intravenous administration of the tracer, and no serious adverse effects associated with the administration of $11 \mathrm{C}$-MET have been reported in the available literature $[6,9]$.

\section{PET/CT WITH 11C-METHIONINE IN NEUROONCOLOGY}

The widest application of PET/CT with 11C-MET is in the diagnosis of brain tumors, first of all the most common gliomas, which are characterized by high mortality $[10,11]$. The big advantage is the verylow tracer uptake in healthy brain tissue. The mechanism of 11C-MET accumulation in pathological lesions is not fully expleined. The most likely explanation for this phenomenon is damage to the natural blood-brain barrier resulting in passive diffusion of the tracer into the tumor tissue with the additional occurrence of active transport to the cancer cell caused by increased proliferation. Thanks to these two mechanisms, a good tumor/background ratio can be obtained [6]. The intensity of 11C-MET uptake in a tumor is associated with its grading and malignancy - in tumors with higher proliferative potential and higher histological malignancy usually higher tracer accumulation is observed [6]. This makes 11C-MET often used in the diagnosis of the effectiveness of surgical treatment and to confirm or exclude recurrence after chemotherapy or radiation therapy. In these situations, imaging with radiological techniques is character- 
ized by low specificity $(24-44,4 \%)$ and may give ambiguous, false positive results in connection with post-treatment necrotic lesions, fibrosis, edema zones or scar lesions [10, 12-14]. In morphological studies, these changes may give an image similar to proliferative lesions. However, they do not show 11C-MET uptake in PET/CT, which allows for fairly accurate differential diagnosis of post-therapeutic changes and recurrence. The sensitivity and specificity of this type of examinations are estimated at over $90 \%$ [10]. In pre-therapeutic diagnostics, PET/CT with 11C-MET can be used to plan radiation therapy and defining tumor boundaries quite accurately, which helps reduce irradiation of healthy tissue, and by narrowing the irradiation field, allows to intensify the absorbed dose in the tumor. PET/CT with 11C-MET may also indicate the potentially most favorable site for biopsy by selecting the area with the highest tracer accumulation. The change in the intensity of 11C-MET accumulation in the tumor in subsequent, repeated studies may be an indicator of a change in the histological grade of the tumor and indicate its differentiation. The clinical manifestations of tumors with high, intensive 11C-MET accumulation seen in PET/CT are usually more rapid, affecting shorter patient survival and mortality. The intensity of 11C-MET accumulation in central nervous system tumors is not affected by corticosteroid treatment for anti-edema purposes [6].

Benign brain lesions, such as meningiomas, may also be characterized by 11C-MET uptake in PET/CT. A comparative study in 22 patients found a higher rate of accumulation of radiolabeled methionine in meningioma lesions compared to the uptake observed in PET/CT with 18-FDG, with better quality images and a better tumor/background ratio, which is caused by a natural, physiological accumulation of 18-FDG in normal brain tissue [15].

Low availability of the tracer in departments that do not have a cyclotron for its production remains the main limitation of the PET/CT with 11C-MET. Due to the physical properties of the 11C isotope and the energy of the positron emitted from its nucleus, the spatial resolution of the method is estimated at about $5 \mathrm{~mm}$, which may also be a certain limitation of the diagnostic capabilities of PET/CT with methionine labeled with this isotope. Currently in Poland, the 11C-MET tracer is not reimbursed by the national public health system in any of the indications, which is significantly limits its use in clinical practice.

A different issue could be pituitary gland tumors. Even in normal, unchanged pituitary gland, physiological accumulation of 11C-MET is observed [16]. The mechanism of 11C-MET uptake in hormonally active adenomas is associated with increased cellular proliferation and with the fact that methionine is one of the substrates needed for hormone synthesis by pituitary cells. In the literature, there is evidence of the usefulness of the PET/CT with 11C-MET in the preoperative diagnosis of pituitary corticotropic adenomas, as well as in the diagnosis of recurrence of ACTH-dependent Cushing's syndrome after surgery [17]. This technique is also useful in the diagnosis of other hormonally active pituitary adenomas, especially in the case of ambiguous or doubtful results obtained in magnetic resonance imaging $[18,19]$.

\section{THE USE OF PET/CT WITH 11C-METHIONINE IN HEMATOLOGICAL AND ONCOLOGICAL DIAGNOSTICS}

Among the various clinical attempts to use the PET/CT 11C-MET study for oncological diagnosis in recent years, the most promising reports show the role of this study in monitoring multiple myeloma. A commonly used marker in myeloma imaging is 18 -FDG, whose effectiveness in initial diagnostics and in assessing the effectiveness of treatment has been confirmed by many studies $[20,21]$. The limitation of this method is often low glucose metabolism and high heterogeneity of pathological lesions. Initial good experiments using 11C-MET PET/CT in the diagnosis of myeloma and the results of in vivo and in vitro studies on CD138 + cells prompted several teams to further research $[22,23]$. A two-center study of 78 patients demonstrated the superiority of PET/CT with 11C-MET over 18-FDG in the detection of myeloid and extramedullary lesions in multiple myeloma, what according to the authors could complete replace glucose tracer by amino acid one in the future [24]. The likely mechanism of 11C-MET uptake in myeloma foci is associated with the incorporation of methionine into immunoglobulin synthesized in lesions, resulting in 11C-MET uptake intensity in a simple way correlating with disease activity, the degree of bone marrow involvement, $ß 2$ macroglobulin concentration and the concentration of free light chains (FLC), which are important prognostic factors in the course of multiple myeloma [24,25]. In another study involving 19 patients with multiple myeloma, higher sensitivity of PET/CT with 11C-MET over PET/CT with 11C-choline in detection of pathological changes was found [26].

Among the other hematological diseases, use of the PET/ CT with 11C-MET in assessment of the early response to methotrexate-based chemotherapy on primary central nervous lymphoma (PCNSL), which has a poor prognosis, deserves mention. A study assessing 26 patients who underwent PET/CT 11C-MET after 4 cycles of high-dose chemotherapy (interim-PET) found that high tracer uptake in interim-PET was associated with a statistically significant reduction in progression-free survival (PFS) and was a bad prognostic factor in the PCNLS [27].

In the literature you can also find reports of individual cases of patients with various types of lymphoproliferative hyperplasia, in whom the PET/CT examination with 11C-MET allowed better assessment of the disease staging, compared to the standard PET/CT examination with 18 -FDG, but currently it is not a standard procedure for lymphoma diagnosis [28].

In the 1990s and at the beginning of the 21st century studies assessing the usefulness of PET/CT imaging with 11C-MET in the diagnosis of solid tumors, especially mammary gland cancer and lung cancer were conducted. However, this work did not bring the expected result. The advantage of diagnostics using 11C-MET over 18-FDG has not been proved, with a much more favorable half-life time of 18-FDG (109min), which allows transporting the tracer even over a considerable distance, which makes PET centers independent of having their own cyclotron $[29,30]$. 
Of the ongoing clinical trials, the large study of $650 \mathrm{pa}-$ tients in St. Jude Children's Research Hospital in Memphis (USA), which aims to assess 11C-MET uptake in all newly diagnosed nervous system tumors and lymphomas and sarcomas of soft tissues and bones, as well as other cancers is worth mentioning. The planned ending of the study is expected in 2023.

\section{THE USE OF PET/CT WITH 11C-METHIONINE IN THE DIAGNOSIS OF HYPERPARATHYROIDISM}

The main method of treating hyperparathyroidism, regardless of its cause, is the surgical removal of the autonomic parathyroid gland. This is the only effective method to cure the disease [31,32]. Traditionally, in the surgical treatment of hyperparathyroidism, to visualize all four parathyroid glands bilateral neck exploration was used, which is a largescale procedure [33]. Nowadays minimally invasive parathyroidectomy (MIP) in surgical treatment is performed more often thanks to improvement in imaging diagnostics [34]. However, precise preoperative localization of the autonomic parathyroid is necessary for this type of surgery.

For preoperative localization, the double-tracer subtraction scintigraphy of parathyroid glands using $99 \mathrm{mTc}$ and 99mTc-MIBI and ultrasound remains the gold standard. Scintigraphy is a sensitive method of detection of a single adenoma, unfortunately its value decreases in the presence of multiple lesions or concomitant focal lesions in the thyroid gland [35]. Even more than $30 \%$ of parathyroid adenomas found in primary hyperparathyroidism do not accumulate the $99 \mathrm{mTc}$-MIBI tracer [36]. In secondary and tertiary hyperparathyroidism, the sensitivity of scintigraphy using $99 \mathrm{mTc}$ and $99 \mathrm{mTc}-\mathrm{MIBI}$ is lower than in the case of primary changes and is assessed $36.6-62.8 \%$, which is a significant diagnostic problem $[37,38]$. The parathyroid glands may be ectopic, located in the mediastinum, being other diagnostic problem. 11C-MET is a substrate for the production of the parathyroid hormone precursor and is therefore actively accumulated in parathyroid gland cells [39]. Studies of the efficacy of the PET/CT test with 11C-MET in the diagnosis of hyperparathyroidism present in the literature were conducted on small heterogeneous groups of patients, presenting various, divergent (from 44 to $84 \%$ ) results of sensitivity and specificity of this examination. However, all the authors claim that this study may complement the pre-operative localization diagnostics of patients with primary hyperparathyroidism, in whom standard double-tracer subtraction scintigraphy and ultrasound do not provide a clear result allowing for effective MIP surgery [40, 41]. In addition, some authors show evidence of the superiority of PET/CT diagnostics with 11C-MET over scintigraphy in patients who have previously undergone surgical treatment and who have recurrent hyperparathyroidism $[42,43]$. Due to the larger scope of the PET/CT scan compared to the scintigraphy, it may also have an advantage in patients with ectopic lesions and multiple lesions, which are more common in secondary and tertiary hyperparathyroidism (e.g. in patients undergoing renal replacement therapy) $[43,44]$. As for the safety of these studies, the absorbed dose that the patient receives from the isotope during the PET/CT with 11C-MET made to assess the location of the parathyroid glands is more than four times lower than the dose absorbed during standard scintigraphy [45].

\section{CONCLUSIONS}

The PET/CT examination with 11C-MET has its well-established position in the diagnosis of brain proliferative diseases, which is confirmed by rich literature. It is also becoming increasingly important in monitoring the treatment of multiple myeloma. It is also useful in the diagnosis of primary, secondary and tertiary hyperparathyroidism.

The limitation of the method is primarily the lack of tracer in hospitals without their own cyclotron. In Poland, the tracer is not reimbursed by the National Health Fund (pol. Narodowy Fundusz Zdrowia) and its use is limited to scientific research.

\section{REFERENCES}

1. Wygoda Z, d'Amico A, Jarząb B, et al. Tomografia emisji pozytonów (PET) i jej zastosowanie do wykrywania, lokalizacji i monitorowania guzów gruczołów wydzielania wewnętrznego. Post Nauk Med 2009;10:840-847

2. Pappenheimer AM. A Biographical Memoir of John Howard Mueller (PDF). Washington D.C.: National Academy of Sciences, 1987.

3. Bigelow DJ, Squier TC. Redox modulation of cellular signaling and metabolism through reversible oxidation of methionine sensors in calcium regulatory proteins. Biochim Biophys Acta. 2005;1703(2):121-4.

4. Miller PW, Long NJ, Vilar R, et al. Synthesis of11C,18F,150, and13N Radiolabels for PositronEmission Tomography Angew. Chem Int Ed 2008:47:8998-9033

5. Caroli P, Nanni C, Rubello D, et al. Non-FDG PET in the practice of oncology. Indian J Cancer. 2010 Apr-Jun;47(2):120-5.

6. Fanti S, Farsad M, Mansi L. PET-CT Beyond FDG A Quick Guide to Image Interpretation. Berlin Heidelberg: Springer-Verlag 2010, pp. 52-61

7. Harris SM, Davis JC, Snyder SE, et al. Evaluation of the Biodistribution of [11C] Methionine in Children and Young Adults J Nucl Med. 2013 Nov;54(11):1902-1908.

8. Quinn B, Dauer Z, Pandit-Taskar N, et al. Radiation dosimetry of 18F-FDG $\mathrm{PET} / \mathrm{CT}$ : incorporating exam-specific parameters in dose estimates BMC Med Imaging. 2016;16:41.

9. Isohashi K, Shimosegawa E, Kato H, et al. Optimization of [11C] methionine PET study: appropriate scan timing and effect of plasma amino acid concentrations on the SUV EJNMMI Res. 2013;3:27.

10. Santoni M, Nanni C, Bittoni A, et al. [11C]-Methionine Positron Emission Tomography in the Postoperative Imaging and Followup of Patients with Primary and Recurrent Gliomas ISRN Oncol. 2014; 2014: 463152.

11 Nevo I, Woolard K, Cam M, et al. Identification of molecular pathways facilitating glioma cell invasion in situ. PLoS One. 2014;9

12. Xu W, Gao L, Shao A, et al. The performance of 11C-Methionine PET in the differential diagnosis of glioma recurrence. Oncotarget. 2017 0ct 31;8(53):91030-91039.

13. Kläsner B, Buchmann N, Gempt J, et al. [18F]FET-PET in Gliomas after Surgical Resection: comparison with MRI and Histopathology. PLoS One. 2015;10

14. KarunanithiS, Sharma P, Kumar A, et al. Comparative diagnostic accuracy of contrast-enhanced MRI and (18)F-FDOPA PET-CT in recurrent glioma. Eur Radiol. 2013;23:2628-35. 
15. Mitamura K, Yamamoto Y, Norikane T, et al. 18F-FDG and 11C-Methionine $\mathrm{PET} / \mathrm{CT}$ in the Assessment of Tumor Grade and Proliferation in Newly Diagnosed Intracranial Meningioma J Nucl Med 2018;59:(1):1687

16. Tomura N, Saginoya T, Mizuno Y, et al. Accumulation of 11C-methionine in the normal pituitary gland on 11C-methionine PET. Acta Radiol. 2017 Mar;58(3):362-366.

17. Koulouri 0 , Steuwe A, Gillett D, et al. A role for 11C-methionine PET imaging in ACTH-dependent Cushing's syndrome. Eur J Endcrin. 2015 0ct;173(4):107-120.

18. Zize F, Dongsheng $F$, Zhigang $M$, et al. Utility of 11C-Methionine and 18F-FDG PET/CT in Patients With Functioning Pituitary Adenomas. Clin Nucl Med. 2016;41(3):130-134

19. Koulouri 0, Hoole AC, English $P$, et al. Localisation of an occult thyrotropinoma with 11C-methionine PET-CT before and after somatostatin analogue therapy. Lancet Diabet Endocrinol 2016;4:1050

20. Bilezikian JP, Brandi ML, Eastell R, et al. Guidelines for the management of asymptomatic primary hyperparathyroidism: summary statement from the Fourth International Workshop. J Clin Endocrinol Metab. 2014 0ct;99(10):3561-9.

21. Pitt SC, Sippel RS, Chen H. Secondary and tertiary hyperparathyroidism, state of art surgical management. Surg Clin North Am. 2009 0ct;89(5):1227-39.

22. Dowthwaite SA, Young JE, Pasternak JD, Yoo J. Surgical management of primary hyperparathyroidism. J Clin Densitom. 2013 Jan-Mar;16(1):48-53.

23. Grant CS, Thompson G, Farley D, van Heerden J. Primary hyperparathyroidism surgical management since the introduction of minimally invasive parathyroidectomy: Mayo Clinic experience. Arch Surg. 2005 May; $140(5): 472-8$.

24. Taieb D, Hindie E, Grassetto G, Colletti PM, Rubello D. Parathyroid scintigraphy: when, how, and why? A concise systematic review. Clin Nucl Med. 2012 Jun;37(6):568-74.

25. Ciappuccini R, Morera J, Pascal $P$, et al. Dual-phase $99 \mathrm{mTc}$ sestamibi scintigraphy with neck and thorax SPECT/CT in primary hyperparathyroidism: a single-institution experience. Clin Nucl Med. 2012 $\operatorname{Mar} ; 37(3): 223-8$.

26. Thaieb $D$, Ureña-Torres $P$, Zanotti-Fregonara $P$, et al. Parathyroid Scintigraphy in Renal Hyperparathyroidism The Added Diagnostic Value of SPECT and SPECT/CT. Clin Nucl Med. 2013 Aug;38(8):630-5

27. Alhhaili E, TasciY, Aksoy E, etal. The utility of neck ultrasound and sestamibi scans in patients with secondary and tertiary hyperparathyroidism. World J Surg. 2015 Mar;39(3):701-5.

28. Cetani F, Marcocci C. The use of positron emission tomography with 11C-methionine in patients with primary hyperparathyroidism. Endocrine 2013 Apr;43(2):251-2.

29. Kluijfhout W, Pasternak JD, Drake FT. Use of PET tracers for parathyroid localization: a systematic review and meta-analysis. Langenbecks Arch Surg. 2016;401(7):925-35.

30. Noltes ME, Coester AM, van der Horst-Schrivers ANA, et al. Localization of parathyroid adenomas using 11C-methionine pet after prior inconclusive imaging. Langenbecks Arch Surg. 2017;402(7):1109-1117

31. Traub-Weidinger T, Mayerhoefer ME, Koperek 0, et al. 11C-methionine $\mathrm{PET} / \mathrm{CT}$ imaging of $99 \mathrm{mTC}-\mathrm{MIBI}-\mathrm{SPECT} / \mathrm{CT}$-negative patients with primary hyperparathyroidism and previous neck surgery. J Clin Endocrinol Metab. 2014 Nov;99(11):4199-205

32. Moller ML, Rejnmark L, Arveschoug AK, Højsgaard A, Rolighed L. Clinical value of $11 \mathrm{C}$-methionine positron emission tomography in persistent primary hyperparathyroidism-A case report with a mediastinal parathyroid adenoma. Int J Surg Case Rep. 2018 Mar 15;45:63-66
33. Tang BN, Moreno-Reyes $R$, Blocklet $D$, et al. Accurate pre-operative localization of pathological parathyroid glands using 11C-methionine PET/CT. Contrast Media Mol Imaging 2008;3(4):157-163

34. Mettler FA Jr, Huda W, Yoshizumi TT, Mahesh M. Effective doses in radiology and diagnostic nuclear medicine: a catalog. Radiology. 2008 Jul;248(1):254-63.

35. Durie BG, Waxman AD, D'Agnolo A, et al. Whole-body (18)F-FDG PET identifies high-risk myeloma. J Nucl Med. 2002;43:1457-63

36. Bartel TB, Haessler J, Brown TL, et al. F18-fluorodeoxyglucose positron emission tomography in the context of other imaging techniques and prognostic factors in multiple myeloma. Blood. 2009;114:2068-76

37. Dankerl A, Liebisch P, Glatting G, et al. Multiple Myeloma: Molecular Imaging with 11C-Methionine PET/CT-Initial Experience. Radiology. 2007;242:498-508

38. Luckerath K, Lapa C, Albert C, et al. 11C-Methionine-PET: a novel and sensitive tool for monitoring of early response to treatment in multiple myeloma. Oncotarget. 2015;6:8418-29

39. Lapa C, Garcia-Velloso MJ, Lückerath K, et al. 11C-Methionine-PET in Multiple Myeloma: A Combined Study from Two Different Institutions. Theranostics 2017;7(11):2956-2964

40. Lapa C, Knop S, Schreder M, et al. 11C-Methionine-PET in Multiple Myeloma: Correlation with Clinical Parameters and Bone Marrow Involvement. Theranostics 2016;6(2):254-261

41. Lapa C, Kircher M, Da Via M, et al. Comparison of 11C-Choline and 11C-Methionine PET/CT in Multiple Myeloma. Clin Nucl Med. 2019 Aug; $44(8): 620-624$

42. Ahn SY, Kwon SY, Jung SH, et al. Prognostic Significance of Interim 11C-Methionine PET/CT in Primary Central Nervous System Lymphoma. Clin Nucl Med. 2018 Aug;43(8):259-264

43. Annunziata S1, Cuccaro A, Caldarella C, et al. Dural MALT Lymphoma Detected by 11C-Methionine PET/CT. Clin Nucl Med. 2017 Dec;42(12):962-963

44. Huovinen R, Leskinen-Kallio S, Någren K, et al. Carbon-11-methionine and PET in evaluation of treatment response of breast cancer. Br J Cancer. 1993 Apr;67(4):787-791.

45. Hubner KF. Can 11C-Methionine Play a Role in Lung Cancer Staging? J Nucl Med. 2000;41:291-292.

\section{ORCID and contributionship}

Maciej Kołodziej - 0000-0003-1943-264X A,B,D

Barbara Bober - 0000-0002-1880-1389 A,E

Marek Saracyn - 0000-0002-5800-0500 A,E-F

Grzegorz Kamiński - 0000-0002-2357-0634 ${ }^{F}$

\section{Conflict of interest}

Authors declare no conflict of interest.

\section{CORRESPONDING AUTHOR Maciej Kołodziej}

Department of Endocrinology and Isotope Therapy,

Military Institute of Medicine,

Szaserów 128, 04-141, Warszawa, Poland

e-mail:mkolodziej@wim.mil.pl

Received: 25.06 .2020

Accepted: 15.09 .2020 